\title{
Preferences of Medical Sciences Students for Work Contracts in Deprived Areas of Iran: A Discrete Choice Experiment Analysis
}

This article was published in the following Dove Press journal: Risk Management and Healthcare Policy

\author{
Ali Kazemi Karyani $\mathbb{1}^{\prime}$ \\ Behzad Karami Matin' \\ Parisa Malekian ${ }^{2}$ \\ Delnia Moradi Rotvandi ${ }^{2}$ \\ Saeed Amini $\mathbb{D}^{3}$ \\ Sajad Delavari (iD ${ }^{4}$ \\ Shahin Soltani ${ }^{1}$ \\ Satar Rezaei (iD)'
}

'Research Center for Environmental Determinants of Health, Health Institute, Kermanshah University of Medical Sciences, Kermanshah, Iran; ${ }^{2}$ Students Researches Committee, Kermanshah University of Medical Sciences, Kermanshah, Iran; ${ }^{3}$ Department of Health Services Management, School of Public Health, Arak University of Medical Sciences, Arak, Iran; ${ }^{4}$ Health Human Resources Research Center, School of Management and Information Sciences, Shiraz University of Medical Sciences, Shiraz, Iran
Correspondence: Satar Rezaei

Research Center for Environmental Determinants of Health, Health Institute, Kermanshah University of Medical Sciences, Kermanshah, Iran

Email satarrezaei@gmail.com
Background: An unequal distribution of human resources affects access to health-care services. This study aimed to elicit the preferences of medical, dentistry, and pharmacy students about attributes of work contracts in deprived areas of Iran; this is a primary important step to decrease inequity.

Methods: Two-hundred and one students were entered into the study through proportional sample size estimation from Kermanshah University of Medical Sciences in the west of Iran in 2018. The attributes of work contracts were determined using the discrete choice experiment (DCE) method, then possible dual scenarios of work contracts were designed through the D-efficiency method of SAS software and the data were collected using a questionnaire designed by the researchers. The conditional logistic model was used to analyze the data.

Results: Salary, workplace, side facilities, scholarship, and workload were considered as important factors for working in the deprived areas $(p<0.001)$. There were differences between the students' preferences regarding their residential areas, majors, and state or tuition-paying education $(p<0.001)$. Higher payments, side facilities, and availability of quota after working in the deprived areas were considered as creators of higher utility, and working in deprived areas and high workload were considered as creators of lower utility $(p<0.001)$.

Conclusion: This study provides new evidence about the preferences of medical sciences students for work contracts in deprived areas of Iran. According to the findings, money is not the only factor that affects the decisions of medical sciences students related to working contracts in deprived areas of Iran. Designing work contracts that are matched with preferences of the workforce can lead to an improvement in equity, access, and utilization of health-care services.

Keywords: preferences, contracts, medical students, deprived areas

\section{Background}

The health workforce is one of the main three inputs of health-care systems in all countries. The performance of health systems is directly dependent on the health workforce. ${ }^{1}$ Low-income countries have a lower density of health workforce and hence achieving social, economic, and health development goals and also improving the quality of services are threatened by shortages in human resources. ${ }^{2,3}$ The density of health workers is associated with important health outcomes such as maternal mortality, infant mortality, and the under-five mortality rate. With an increase in health workers, the mortality rates will decrease. Also, coverage of 
health services and health outcomes are directly associated with the density of the health workforce. ${ }^{2,4,5}$

Alongside shortages in health workers, the distribution of human resources between different areas of countries is usually unequal. Advantaged areas are more attractive for health workers. So, deprived areas of countries do not absorb a proportional percentage of health workers and suffer from insufficient forces. ${ }^{6,7}$ Related challenges to health workers such as shortages of health workers (particularly nurses and physicians), misdistributions and imbalance in skill mix, the aging workforce, poor working conditions, and educational reforms affect many low and middle income countries such as Iran. ${ }^{8,9}$ Different studies have shown an imbalanced distribution of health resources in the Iranian health system. According to these studies, there are geographical inequalities in the distribution of health workers, so that deprived areas of the country have lower density of health workers than advantaged ones. ${ }^{10,11}$

The health system in Iran is designed to be integrated. The Ministry of Health and Medical Education (MoHME) is responsible for public health and policymaking in health. The MoHME performs its duties through medical universities located in the provinces of Iran. One of the most important functions of medical universities is to provide health services. The district health network has provided access for people through a referral system. There are three levels of services in this network. The first level provides primary health-care services. This level is compromised health house and rural comprehensive health centers in rural areas and health post and urban comprehensive health centers in urban areas. If people need more specialized services, they are referred to general hospitals and teaching hospitals through the referral system. In addition, the private sector has a considerable role in providing services in Iran's health system. This sector is more focused on secondary and tertiary services. Figure 1 shows the nationwide health network in Iran. ${ }^{12}$

Medical universities affiliated with the MoHME play a key role in training the human resources of the health sector. Due to the disproportionate distribution of manpower, we are witnessing a shortage of manpower in deprived and underprivileged areas of the country. The prevalent reasons for lack of motivation to work in deprived areas are low and irregular salaries, high working load, lack of job security, and high responsibility. ${ }^{13}$ Also, medical universities failed to produce appropriate and interested health workers to work in deprived areas and the primary health-care systems. ${ }^{14}$ To reduce the problems of attracting manpower to

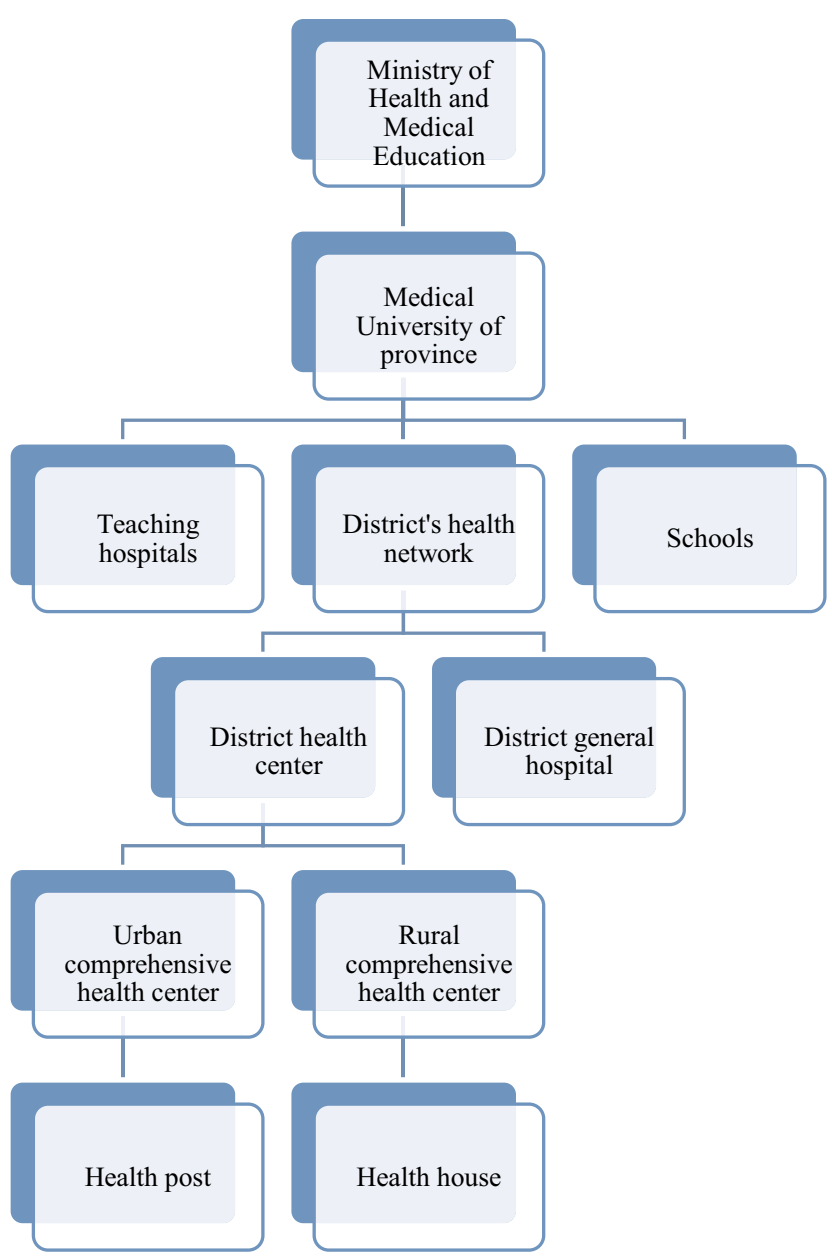

Figure I Schematic picture of the health system network in Iran.

disadvantaged areas, the MoHME requires some graduates of medical sciences, such as physicians, dentists, pharmacists, and nurses, to work in disadvantaged and rural areas for a certain period of time, but despite such actions, there are many problems in attracting and retaining human resources in underserved areas of Iran. ${ }^{12}$

The preferences of health workforces are among the key elements in the recruitment of human resources in rural and deprived areas. In other words, evidence about the preferences of health workers is critical for designing programs to improve the distribution of health workers in favor of deprived areas. ${ }^{15}$ Two studies in Iran have investigated the preferences of general practitioners for entrance in the family physician plan (FPP). They have studied the preferences of the participants for attributes of possible work contracts. ${ }^{16,17}$ FPP was implemented in Iran in 2005 to improve access to primary health services for the rural population, and the Iran Health Insurance Organization (IHIO) provides financial resources for this plan. In the FPP, the general practitioner and a health-care team 
(including dentist, midwife, and other health workers) are responsible for the population's health, and patients who need more complicated care will be referred to specialists and hospitals. The health-care team is also responsible for following up on the treatments taken. Health centers that provide health services for rural residents and deprived areas of cities usually face problems regarding attraction and retention of the health workforce, especially physicians, dentists, and pharmacists. Medical education programs, work conditions, and monetary and non-monetary incentives are important factors affecting the attraction and retention of the workforce in underserved areas. However, preferences of the health workforce for attributes of work contracts are important for planning to improve recruitment and retention of human resources. Preferences of medical students also should be considered in human resources management. This evidence is useful for the revision of medical education programs and for better planning for the recruitment of future graduates of medical universities. ${ }^{13,14,18}$ There is limited evidence about the preferences of medical sciences students in Iran, especially for work in deprived areas of the country. Considering the importance of the subject, this study aimed to elicit the preferences of medical, dentistry, and pharmacy students at Kermanshah University of Medical Sciences about the various attributes of work contracts in deprived areas using the discrete choice experiment (DCE) method of analysis. The DCE method is frequently used in the health-care sector ${ }^{19,20}$ and one of the most frequent applications of this economic method is to elicit preferences of the health workforce and medical sciences students in deprived areas, especially in low-and middleincome countries (LMICs). ${ }^{21-24}$ In achieving the aim of this study, students were presented with a choice of 7 contracts at varying levels of the same characteristics. The students' preferences were explored within a discrete choice model. Discrete choice models are used to model choices a student (or a consumer) might make between well-defined alternatives in a real-world context, as opposed to exploring perceptions of an ideal work contract. The findings of this study can be helpful for health-care policymakers to design optimal contracts and increase human resources recruitment in deprived areas of the country.

\section{Methods}

This study was performed using the discrete choice experiment (DCE) method to elicit the stated preferences of medical students in the west of Iran. The stated preferences are related to empirical studies that hypothetical choice situations suggest to participants. The "stated" term refers to the fact that people make their choices in hypothetical situations. The important assumption for the stated preferences is that the values that individuals express are in fact the same ones that exist in their daily lives, and that the choices they make in the survey are the same ones they would make when faced with the same choices in the real world. ${ }^{25}$ This method can help to understand the mechanism of the selection process and the tradeoffs that individuals tend to make. ${ }^{26} \mathrm{DCE}$ is a multi-step method that is performed through a few steps. ${ }^{27}$

\section{Defining Attributes and Attribute-Levels}

One of the main issues in developing a work contract is to identify attributes that define them. There are some standard attributes such as remuneration (eg, salary, holiday entitlement) and the level at which these attributes are defined, eg, every organization and discipline has a predefined set of salary scales and remuneration packages. The expectation is often that new graduates start at the bottom of the scale. However, in cases where it is difficult to recruit staff, eg, recruiting and retaining medical professionals in rural or deprived areas, additional attributes, and/or higher levels of existing attributes may be offered to attract more candidates. Based on the literature and discussions with six experts, a set of attributes and their levels were identified. Experts had at least three years' experience in health-care management and/ or work in deprived areas. They were interviewed about the factors that affect recruitment and retention of the health workforce in deprived areas. After that, we extracted a candidate list of attributes and levels. Finally, the research team selected the final attributes and levels. The final attributes (levels) were payment (capitation/capitation $+30 \%$ bonus/capitation $+50 \%$ bonus), place of medical center (own province/a nearby province/a faraway province), financial settlements (max to 15 days/between 15 and 30 days/ between 30 and 60 days), housing and transportation facilities (no/yes), duration of contract (one year/3 years/5 years), quotations for continuing education (no/after 4 years' work in deprived area(s)/after 8 years' work in deprived area(s)), and workload (low/moderate/heavy).

\section{Experimental Design}

After identification of attributes and attribute-levels, we designed dual generic scenarios using fractional factorial design so that in each choice set the participants selected one of the alternative work contracts that they preferred. As we included 20 attribute-levels in our design, 21 choice sets were made. ${ }^{28}$ Therefore, to decrease the cognitive load of choices on participants, the final choice sets were 
placed in three blocks, each block including eight choice sets. We used expert opinion during the process of identification of attributes and levels and choice sets were designed using experimental design. Therefore, the questionnaire was valid to measure the preferences of participants. Also, one of the choice sets was a dominant choice set to test the consistency of responses that were not included in the final analysis. The dominant choice set is a choice set where all attribute-levels in one scenario are preferred to an alternative one. So, we expected to participant choose this scenario in the dominant choice set. The persons who presented wrong answers to the dominant choice set, as inconsistent answers were excluded from the analysis. One of the included choice sets in this study is shown in Appendix 1. The experimental design was performed through the D-efficiency method using SAS software version 9.3. Data analysis performed by Stata version 14 (StataCorp, College Station, TX, USA).

Finally, we designed a questionnaire for data collection. The first part of the questionnaire includes demographic and social characteristics and the second includes choice sets related to the work contracts, which consists of the combination of attributes and levels. There were three editions of the questionnaire which were distributed among the participants equally and randomly. Each participant only answered one edition of the questionnaire. As the attributes and levels of work contracts were similar in all blocks of choice sets, data collected from the different questionnaires were analyzed together.

\section{Sample Size and Study Population}

The study population included the students from medical, pharmacy, and dentistry majors studying in Kermanshah University of Medical Sciences (KUMS) located in Kermanshah city in the west of Iran. Three schools of medicine, dentistry, and pharmacy entered the study. The manpower related to these fields is less than other fields and there are usually more problems in attracting these workforces in the Iranian health system. That is why we investigated the preferences of students in these three majors. The sample size of the study was calculated by the following formula: ${ }^{29}$

$$
(n t a / c)>500
$$

where $n$ is the total number of participants, $t$ is the total number of choice sets, $a$ is the total number of alternatives in the choice sets, and $c$ denotes the highest number of levels in the included attributes. In this study, $n$ equals 250 students, $t$ equals $7, a$ equals 2 , and $c$ equals 3 . With these parameters inserted in the above formula, the threshold was 1166 that is higher than the minimum threshold (500) that has been suggested as an indicator of a sufficient sample size in DCE studies. However, 281 students were included to increase the power of the study. Therefore, among students of medicine, dentistry, and pharmacy, 281 participants were entered into the study to fulfill the threshold. The number of students in each major was determined through proportional size estimation. To increase the accuracy of data collection, the questionnaires were completed with face to face interview. A convenience sampling method was used for data collection. Two trained senior public health students conducted the interviews under the supervision of the research team.

\section{Statistical Analysis}

The random utility model (RUM) provides a theoretical base to the analysis of DCE data. ${ }^{30}$ In this framework, it is assumed that person $\mathrm{n}$ should choose among $\mathrm{j}$ options and choose the option with most utility for him/her. So, this person will choose option i against $\mathrm{j}$, only if: ${ }^{27}$

$$
\mathrm{U}_{\mathrm{ni}}>\mathrm{U}_{\mathrm{nj}} \forall \mathrm{i} \neq \mathrm{j} \in
$$

In which, $U$ is the utility of a given work contract.

Based on the RUM, the utility of a special job (U) is comprised of 2 components.

The random component of $V_{n i}$ that is a function from $\mathrm{m}$ characteristics of work contracts $(\mathrm{X} 1, \ldots \mathrm{Xm})$ which is observable, and the component of $\varepsilon_{n i}$ which is a function of unobservable characteristics and difference in the taste of individuals. So, the utility (U) of work contracts for the individual $\mathrm{n}$, is described as below:

$$
U_{n}=V_{n}+\varepsilon_{n}=\beta_{1} x_{1 n}+\beta_{2} x_{2 n}+\ldots+\beta_{m} x_{m n i}+\varepsilon_{n}
$$

where the beta coefficients $(\beta)$ provide quantitative information about the strength of preferences for each level of attributes, trade-offs, and the forecast of acceptance work contract scenario.

A conditional logistics model was used for DCE analyses. The following model was fitted to elicit the utility of work contracts:

$$
\begin{aligned}
U_{n}= & \beta_{1} \text { Pay }_{2}+\beta_{2} \text { Pay }_{3}+\beta_{3} \text { Place }_{2}+\beta_{4} \text { Place }_{3}+\beta_{5} \text { Settel }_{2} \\
& +\beta_{6} \text { Settl }_{3}+\beta_{7} \text { Fac }_{2}+\beta_{8} \text { Dur }_{2}+\beta_{9} \text { Dur }_{3}+\beta_{10} \text { Quot }_{2} \\
& +\beta_{11} \text { Quot }_{3}+\beta_{12} \text { Load }_{2}+\beta_{13} \text { Load }_{3}+\varepsilon_{n}
\end{aligned}
$$

where $\beta 1$ to $\beta 13$ are the coefficients of included attributelevels of Pay $2=$ level 2 of payment attribute (capitation $+30 \%$ bonus), Pay3 = level 3 of payment attributes 
(capitation $+50 \%$ bonus), Place $2=$ level 2 of the place of medical center attribute (a nearby province), Place3 = level 3 of the place of medical center attribute (a distant province), Settl $2=$ level 2 of financial settlements (between 15 and 30 days), Settl3 = level 3 of financial settlements (between 30 and 60 days), Fac2 = level 2 of housing and transportation (yes), Dur2 = level 2 of duration of contracts (3 years), Dur3 = level 3 of duration of contracts (5 years), Quot2 = level 2 of quotations for continuing education attribute (after 4 years' work in a deprived area(s)), Quot3 = level 3 of quotations for continuing education attribute (after 8 years' work in a deprived area(s)), Load $2=$ level 2 of workload attribute (moderate), Load3 = level 3 of workload attribute (heavy). Level one of each attribute was the base of the estimation and interpretation of coefficients of other levels $(\beta=0$ / OR $=1$ ).

The positive (negative) coefficient in this model means that attribute-levels make utility (disutility) for the participants. This model has a restrictive assumption of independence of irrelevant alternatives (IIA). However, evidence shows that this model is as efficient as other complicated models such as mixed and nested logit models and it is suggested to analyze the DCE data. ${ }^{31}$ Also, the attributes of work contracts were homogeneous. For example, all participants would like to have more salary. In this case, it is better to analyze DCE data using the conditional logit model. Therefore, we performed the conditional logit model to elicit the preferences of participants of this study.

\section{Results}

\section{General Findings}

One-hundred and forty-five $(51.60 \%)$ of the participants were men. The mean age of the participants was 23.33 $(\mathrm{SD}=2.64)$. Regarding the major of participants, $52.31 \%$, $24.56 \%$, and $23.13 \%$ were studying in medicine, pharmacy, and dentistry majors, respectively. About $63 \%$ of participants were senior students in their major. Of all participants, $62.27 \%$ considered wages to be very important. Sixty-five percent of the women and 59\% of the men considered the salary rate very important to choose work contracts. The response rate was $68.49 \%$. There was a significant difference between men's and women's preferences about the salary amount $(p<0.001)$. More than $56 \%$ of the women and $43.7 \%$ of the men considered the role of place of medical centers in choosing work contracts very important. This difference between women and men was statistically significant $(p<0.001)$ (Table 1).

About $51 \%$ of the women and $47 \%$ of the men considered the time of payment very important. The role of housing and transportation facilities was evaluated by women as a more important factor than men when choosing work contracts in deprived areas $(p<0.001)$ (Table 1). There was a significant difference between men and women regarding the duration time of the contracts $(p<0.001)$. The women gave higher weight than the men to the granting of scholarships to continue education $(p<0.001)$. The importance of workload in choosing a work contract in deprived areas was different between men and women, with the women considering this attribute more important $(p<0.001)$. Regarding the importance of workload in closing the contract, the results indicated that $20 \%$ of the men and $41 \%$ of the women considered this attribute very important. In total, the women placed higher weights on the workload $(p<0.001)$ (Table 1 and Figure 2).

\section{Total Preferences of Participants}

On the basis of the conditional logit model, higher payments, availability of housing and transportation facilities, and granting scholarship to continue education will create utility for the students. Capitation payment adding $30 \%$ and $50 \%$ reward in comparison with capitation solely will increase the odds of choosing work contracts in the deprived areas $1.38(95 \% \mathrm{CI}=1.174$, 1.624) and 2.14 times (95\% CI=1.823-2.513), respectively. Capitation payment adding 50\% reward will create the most utility for the study participants. Working in the deprived areas outside the residential place of the students will create disutility for them, so that the service delivery in cities far from the residential areas will create the most disutility for them $(95 \% \mathrm{CI}=-1.09$, $-0.76)(\beta=-0.926)$. The presence of housing and transportation facilities will increase the costs by 1.23 times $(p<0.001)$. The longer the payment time, the higher the contract disutility, so that it will decrease the odds of choosing that contract $(p<0.001)$. The availability of a quota for continuing education on condition of 4 years' working in the deprived areas will increase the odds of contract acceptance to $24 \%$, but the quota on condition of 8 years' working in the deprived areas will decrease the odds of contract acceptance to $25 \%$ in comparison with when there is no such quota $(p<0.001)$. High workload will create disutility too and 
Table I The Importance of Work Contracts' Attributes from the Perspective of Participants in a Likert Scale (I the Highest and 5 the Lowest Importance)

\begin{tabular}{|c|c|c|c|c|c|}
\hline Attributes & Importance & Female (\%) & Male (\%) & Total (\%) & $P$-value \\
\hline Wage & $\begin{array}{l}1 \\
2 \\
3 \\
4 \\
5 \\
\text { missing }\end{array}$ & $\begin{array}{l}89(65.44) \\
35(25.73) \\
10(7.35) \\
0(0) \\
0(0) \\
2(1.47)\end{array}$ & $\begin{array}{l}86(59.31) \\
50(34.48) \\
9(6.20) \\
0(0) \\
0(0) \\
0(0)\end{array}$ & $\begin{array}{l}175(62.27) \\
85(30.24) \\
19(6.76) \\
0(0.00) \\
0(0.00) \\
2(0.07)\end{array}$ & $<0.001$ \\
\hline Place of medical center & $\begin{array}{l}1 \\
2 \\
3 \\
4 \\
5 \\
\text { missing }\end{array}$ & $\begin{array}{l}77(56.62) \\
46(33.82) \\
8(5.88) \\
2(1.47) \\
0(0) \\
3(2.21)\end{array}$ & $\begin{array}{l}59(40.70) \\
69(47.58) \\
13(8.96) \\
3(2.09) \\
0(0) \\
1(0.69)\end{array}$ & $\begin{array}{l}\text { I } 36(48.40) \\
\text { II } 5(40.92) \\
21 \text { (7.47) } \\
5(1.78) \\
0(0.00) \\
4(1.42)\end{array}$ & $<0.001$ \\
\hline Payment time & $\begin{array}{l}1 \\
2 \\
3 \\
4 \\
5 \\
\text { missing }\end{array}$ & $\begin{array}{l}70(5 \mathrm{I} .47) \\
48(35.29) \\
\mathrm{I} 4(10.29) \\
\mathrm{I}(0.73) \\
0(0) \\
2(1.47)\end{array}$ & $\begin{array}{l}68(46.89) \\
60(41.38) \\
13(8.96) \\
4(2.76) \\
0(0) \\
0(0)\end{array}$ & $\begin{array}{l}\text { I38 (49.II) } \\
108(38.43) \\
27(9.6 \mathrm{I}) \\
6(2.14) \\
0(0.00) \\
2(0.7 \mathrm{I})\end{array}$ & $<0.001$ \\
\hline Housing and transportation facilities & $\begin{array}{l}1 \\
2 \\
3 \\
4 \\
5 \\
\text { missing }\end{array}$ & $\begin{array}{l}63(46.32) \\
57(4 I .91) \\
14(10.29) \\
0(0) \\
0(0) \\
2(1.47)\end{array}$ & $\begin{array}{l}43(29.65) \\
65(44.83) \\
34(23.45) \\
3(2.07) \\
0(0) \\
0(0)\end{array}$ & $\begin{array}{l}106(37) \\
I 22(43.4 I) \\
48(I 7.08) \\
3(I .07) \\
0(0) \\
2(0.7 \mid)\end{array}$ & $<0.001$ \\
\hline Contract time & $\begin{array}{l}1 \\
2 \\
3 \\
4 \\
5 \\
\text { missing }\end{array}$ & $\begin{array}{l}55(40.44) \\
65(47.79) \\
\text { I2 (8.82) } \\
\text { I ( } 0.73) \\
\text { I }(0.73) \\
2(1.47)\end{array}$ & $\begin{array}{l}43(29.65) \\
66(45.52) \\
33(22.76) \\
2(1.38) \\
I(0.68) \\
0(0)\end{array}$ & $\begin{array}{l}98(34.87) \\
|3|(46.62) \\
45(|6.0|) \\
3(I .67) \\
2(0.7 \mid) \\
2(0.7 \mid)\end{array}$ & $<0.001$ \\
\hline Scholarship & $\begin{array}{l}1 \\
2 \\
3 \\
4 \\
5 \\
\text { missing }\end{array}$ & $\begin{array}{l}56(41.18) \\
45(33.09) \\
25(18.38) \\
4(2.94) \\
3(2.21) \\
3(2.21)\end{array}$ & $\begin{array}{l}47(32.4 I) \\
5 I(35.17) \\
36(24.83) \\
8(5.52) \\
3(2.07) \\
0(0)\end{array}$ & $\begin{array}{l}103(36.65) \\
96(34.16) \\
61(21.71) \\
12(4.27) \\
6(2.14) \\
3(1.07)\end{array}$ & $<0.001$ \\
\hline Workload & $\begin{array}{l}1 \\
2 \\
3 \\
4 \\
5 \\
\text { missing }\end{array}$ & $\begin{array}{l}57(4 I .9 I) \\
5 I(37.50) \\
20(\mid 4.7 I) \\
5(3.68) \\
1(0.73) \\
2(I .47)\end{array}$ & $\begin{array}{l}29(20) \\
74(51.03) \\
40(27.58) \\
2(1.38) \\
0(0) \\
0(0)\end{array}$ & $\begin{array}{l}86(30.60) \\
125(44.48) \\
60(2 I .35) \\
7(2.49) \\
I(0.36) \\
2(0.7 I)\end{array}$ & $<0.001$ \\
\hline Total (\%) & & $136(48.40)$ & $145(51.60)$ & $281(100)$ & \\
\hline
\end{tabular}

will significantly decrease the odds of acceptance work contracts $(p<0.001)$. The model Pseudo R2 was 0.136 which is statistically significant $(p<0.001)$ (Table 2$)$.
The subgroup analysis compares the preferences of participants regarding different factors as follows (Table 3): 


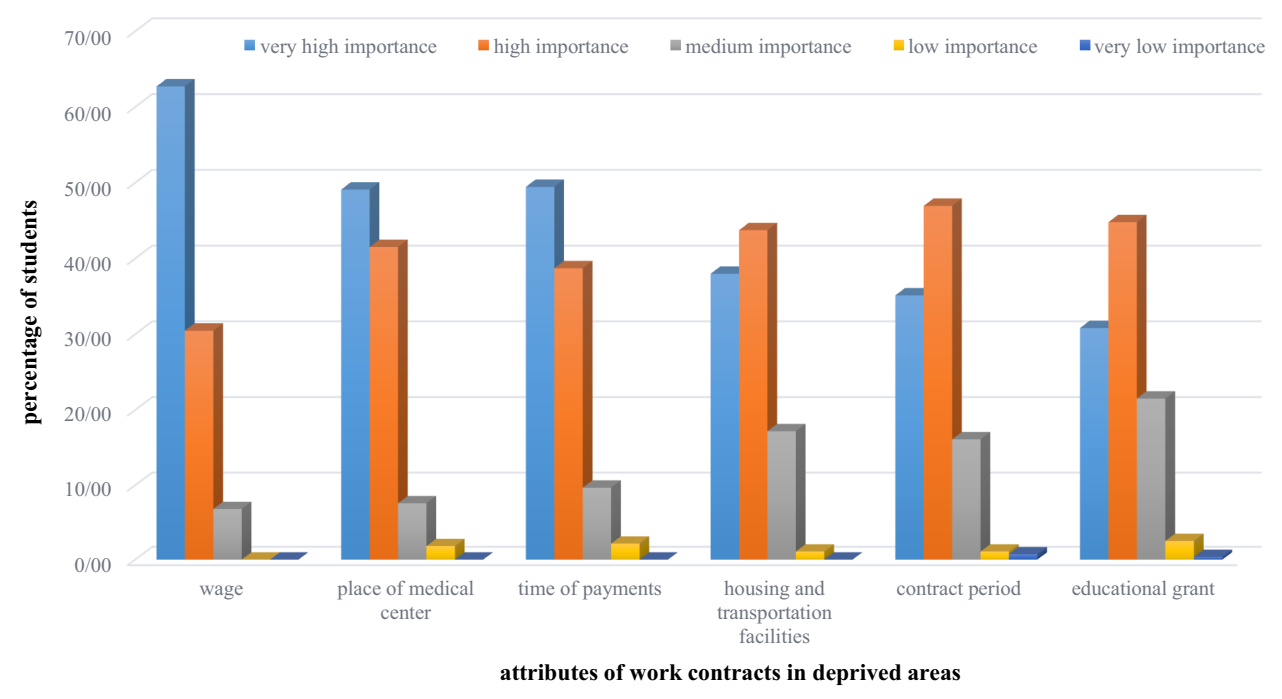

Figure 2 Opinion of medical group students about importance of work contracts' attributes.

\section{Effect of Gender}

There was no significant difference between the two genders regarding the effect of payment method on choosing the contracts. Disutility of working in remote provinces was higher among the men. Working in a remote province rather than working in the residential province of the students will decrease the odds of choosing the contracts by $68 \%$ and $73 \%$ for women and men, respectively. Long payment time and increasing duration of contract will decrease the utility of contract packages for two genders. The presence of a quota for continuing education after 4 or 8 years' working will create disutility for women and utility for men. Moreover, the availability of a quota for continuing education after 4 years' working in the deprived areas will increase the odds of choosing the contract 1.67 times more than when there is no such quota $(p<0.001)$.

\section{Effect of Place of Birth}

Regarding the place of birth, the utility of payment rate for students born in villages was higher than for students born in cities. Capitation and 50\% reward rather than capitation solely will increase the odds of choosing the contract in students born in villages by 1.72 times and in students born in cities by 2.12 times $(p<0.001)$. Disutility of working in remote provinces was higher in city-born students in comparison with village-born students, so that the odds of accepting work contracts in a remote province rather than the residential province were roughly $61 \%$ lower for the students born in cities $(p<0.001)$. The availability of housing and transportation facilities had more attraction for students born in villages $(p=0.190)$. The utility of housing and transportation facilities for the village-born students was twice that for the city-born students. The availability of a quota after 4 years' working in the deprived areas created similar utilities for all to genders, also a high work burden created disutility for both genders.

\section{Effect of Profession}

Regarding educational majors, more payments will create more utilities for the students in all 3 majors. Pharmacy students will enjoy higher utility than other majors regarding higher payments, so that availability of capitation along with $50 \%$ reward rather than capitation solely will increase the odds of choosing the contract by 2.6 times $(p<0.001)$. Working in a remote province will create the most disutility for pharmacy students. The probability of accepting work contracts in a remote province was $72 \%$ lower than working in the residential province in pharmacy students $(p<0.001)$. The availability of a quota for continuing education after 4 years' working in the deprived areas will create utility for all 3 majors, but the availability of a quota after 8 years' working in these areas will create little utility for pharmacy students and has no utility for other students. A high working burden will create disutility for students of all 3 majors, but this disutility for pharmacy students was higher than others $(\beta=$ $-0.58, p<0.01)$.

\section{Effect of Tuition}

Financial rewards will create more utilities for tuitionpaying students. The odds of choosing a work contract in 
Table 2 The Results of Conditional Logit Model of the Effect of Choosing Work Contracts on the Students' Utilities

\begin{tabular}{|c|c|c|c|c|c|}
\hline Choice & Coef & {$[95 \% \mathrm{Cl}]$} & aOR & {$[95 \% \mathrm{CI}]$} & $P$-value \\
\hline \multicolumn{6}{|l|}{ Payment (base: capitation) } \\
\hline Capitation $+30 \%$ bonus & 0.323 & $(0.160,0.485)$ & 1.381 & $(1.174,1.624)$ & $<0.001$ \\
\hline Capitation $+50 \%$ bonus & 0.761 & $(0.60 I, 0.92 I)$ & 2.140 & $(1.823,2.513)$ & $<0.001$ \\
\hline \multicolumn{6}{|c|}{ Place of medical center (base: own province) } \\
\hline A nearby province & -0.509 & $(-0.656,-0.361)$ & 0.601 & $(0.518,0.696)$ & $<0.001$ \\
\hline A faraway province & -0.926 & $(-1.087,-0.764)$ & 0.396 & $(0.337,0.465)$ & $<0.001$ \\
\hline \multicolumn{6}{|c|}{ Financial settlements (base: $\max$ to 15 days) } \\
\hline Between 15 to 30 days & -0.059 & $(-0.223,0.105)$ & 0.942 & $(0.799,1.110)$ & 0.479 \\
\hline Between 30 to 60 days & -0.137 & $(-0.304,0.030)$ & 0.872 & $(0.737,1.03 \mathrm{I})$ & 0.109 \\
\hline \multicolumn{6}{|c|}{ Housing and transportation facilities (base: no) } \\
\hline Yes & 0.209 & $(0.066,0.35 I)$ & 1.232 & $(1.068,1.420)$ & 0.004 \\
\hline \multicolumn{6}{|l|}{ Duration of contract (base: one year) } \\
\hline 3 years & -0.068 & $(-0.221,0.086)$ & 0.935 & $(0.801,1.089)$ & 0.389 \\
\hline 5 years & -0.120 & $(-0.297,0.058)$ & 0.887 & $(0.742,1.059)$ & 0.187 \\
\hline \multicolumn{6}{|c|}{ Quotations for continuing education (base: no) } \\
\hline After 4 years' work in deprived area(s) & 0.220 & $(0.066,0.374)$ & 1.246 & $(1.068,1.453)$ & 0.005 \\
\hline After 8 years' work in deprived area(s) & -0.025 & $(-0.189,0.138)$ & 0.975 & $(0.827,1.149)$ & 0.763 \\
\hline \multicolumn{6}{|l|}{ Workload (base: low) } \\
\hline Moderate & 0.022 & $(-0.132,0.176)$ & 1.022 & $(0.876,1.192)$ & 0.780 \\
\hline Heavy & -0.221 & $(-0.369,-0.073)$ & 0.802 & $(0.691,0.928)$ & 0.003 \\
\hline Observations & \multicolumn{5}{|l|}{3934} \\
\hline Log likelihood & \multicolumn{5}{|l|}{-1178} \\
\hline Pseudo R2 & \multicolumn{5}{|l|}{0.136} \\
\hline Prob > chi2 & \multicolumn{5}{|l|}{$<0.001$} \\
\hline
\end{tabular}

Abbreviations: Coef, coefficient; aOR, adjusted odds ratio; $\mathrm{Cl}$, confidence Interval.

this group when paying a 50\% reward to them were 2.64 times higher than the situation when paying the capitation solely $(p<0.001)$. Disutility of working in remote provinces for tuition-paying students was somewhat lower than for other students. A longer contract time will create more disutility in tuition-paying students than for other students (Table 3).

\section{Discussion}

This study, on one hand, was performed to find the preferences of students regarding work contracts in underserved areas. The main motivation for this was to determine how to provide the required background to boost the supply of medical group students into underserved rural and out-of-reach regions of the country. The study indicated that wage is the most important item that appears in contracts, ie, most students look for higher wages in their contracts to work in rural and underserved areas. Financial incentives have been reported as the most effective strategy for working in rural areas in many countries. ${ }^{19,26}$ An Iranian experience also suggested that increasing salary is among the three factors effective on physicians' retention in rural areas and higher financial incentives to work in underserved regions is an important health policy intervention to equally distribute medical group graduates. Studies have indicated that financial-incentive programs have increased the number of different medical groups working in underserved regions. ${ }^{21}$ Bradley Eide's study on key factors for physician recruitment and retention in rural Wisconsin hospitals indicated that a competitive salary and benefits package is one of the 10 key factors in physician recruitment and retention. ${ }^{18}$

Another issue about payment is financial settlement, which is important for most of the students. They prefer contracts that are paid earlier. Developing countries such as Iran suffer from a high inflation rate which most of the time is over $20 \%$; this decreases the value of the earned 


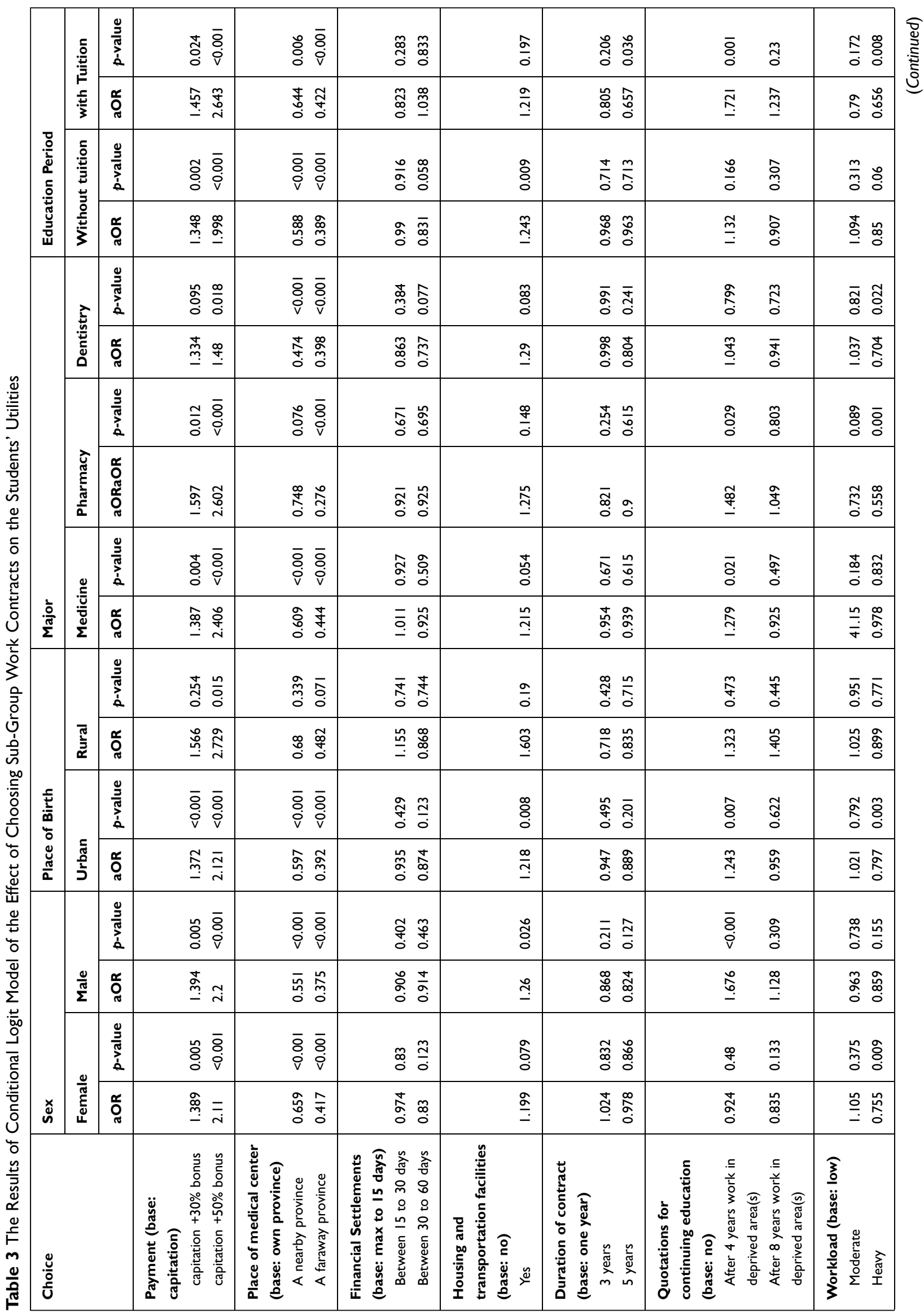




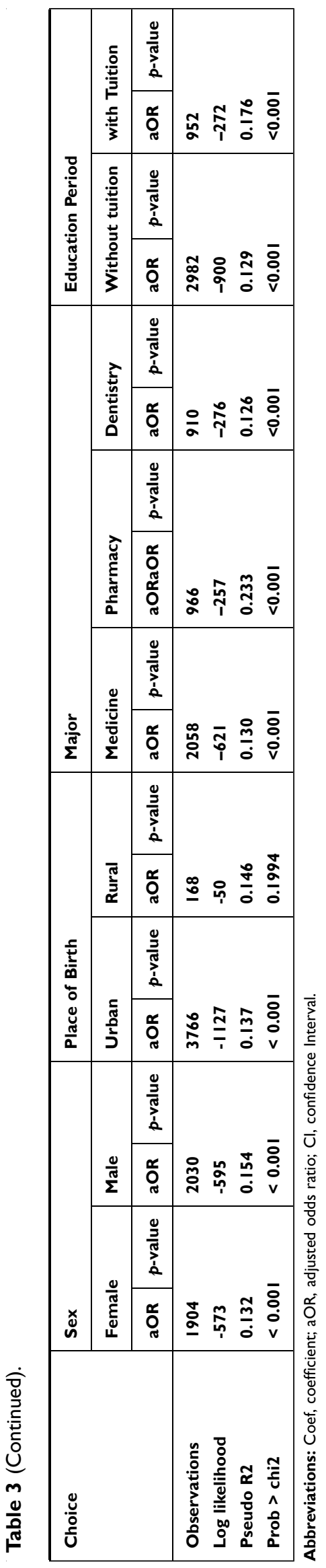

money. In some periods, the exchange rate was doubled only in two or three months. ${ }^{32}$

Students prefer places that are near their hometown for working, so that remote provinces have the least attraction for them. In this regard, it has been indicated that harmony and belonging to rural areas are a good predictors for the retention of dentists. ${ }^{26}$ Another study indicated that native health workers had better communication with their own population, which was reported as a key factor for the retention of expert physicians in Cape Town rural areas. The same findings were reported for nurses; those who belonged to a particular area had fewer tendencies to leave. ${ }^{20}$ Generally, it has been proven globally that medical workers recruited from rural backgrounds are more likely to continue working in rural areas, ${ }^{28,33}$ which has been emphasized by World Health Organization (WHO) in terms of admission of medical group students from rural and deprived areas to medical universities. ${ }^{12}$ Therefore, it can be concluded that the implementation of student admission policies that consider some quota for students of deprived areas is probably a practical solution to the recruitment and retention of the health workforce in these areas. The native health workers are familiar with the living conditions and culture in underserved areas. One of the successful experiences of Iran in this regard is the training of community health workers, called Behvarz, to work in rural areas of this country. They provide primary health care in rural and remote areas. ${ }^{33}$

This study confirms previous evidence which suggests family life and living facilities as one of the main concerns of health human resources. ${ }^{24,28}$ This is an important issue for all students irrespective of gender, origin from rural or urban background, major, and education period. The contracts that suggest housing and transportation facilities in underserved areas are more attractive for human resources. One of the causes may be their concerns about their families. ${ }^{13,14}$ Inadequate infrastructure in rural areas could decrease physicians' tendency to work in underserved areas. ${ }^{19,34}$ Therefore, policymakers should consider expanding living facilities in the health center as it is possible. This can improve the chance of attracting health workers.

When recruiting and contracting medical group students, paying attention to their desire to work in underserved regions is a priority. Another step is considering a change in their preferences over time, due to changes in their lifestyle and situation, including marriage, registering their children in schools, living with parents, the need to 
continue their education, and so on. Living and professional support, and creating and improving the relationship between medical graduates who work in underserved regions and between them and native rural people can increase preference for and retention in these regions. ${ }^{19}$

A systematic review study indicated that among the most important factors causing decreased motivation to work in out-of-reach areas are poor health-care management, high workload, and lack of infrastructure. ${ }^{22}$ Providision of many of these factors and infrastructure is not the responsibility of the health sector or ministry of health. Hence, local and central governments should work along with the health sector to provide the needed background such as telecommunications, road connectivity, housing, and water in the deprived areas. These measures will not come to an end not only with high national political commitment and leadership.

The importance of the contract period is another factor, which has been emphasized before. ${ }^{31}$ Most students do not consider working in rural areas as a permanent or longterm option. Maybe due to obligations from the government, ${ }^{35}$ they want to pass a two-year period in rural areas and then they go to affluent areas for the rest of their working life. So, professional security has been suggested as an incentive for retention in rural areas. ${ }^{26}$

Opportunity for continuing education is one of the main demands of physicians who work in rural and underserved areas. ${ }^{34}$ The same finding was reported in Bangladesh for physicians and nurses. ${ }^{36}$ A qualitative study revealed that Iranian general physicians are not satisfied with their job completely and they are seeking a degree in their area of expertise. ${ }^{37}$ Thus, they look at rural working as an opportunity for this personal aim.

Heavy workload is acceptable for most of the students. Different studies have indicated that bad working conditions resulted in a low supply of health workers in some regions. ${ }^{21,34}$ Studies in Malawi and Uganda have indicated that high after-hours workload in remote areas is the leading factor, among numerous ones, which deter the graduates to work in these areas. ${ }^{23,24}$

This study has many administrative implications for the health-care system of countries regarding how to bring services closer to where people work or live. The baseline important thing which all the authorities accept is the necessity of providing universal health coverage to all of the country, near or remote, urban or rural. However, there is no national commitment to provide health-care services all over the country using university-educated graduates. In this regard, it is necessary to hold highlevel meetings with the presence of authorities of social infrastructures including hospitals, schools and universities, community housing, transportation, and others to assess the ways to attract medical graduates to the deprived areas, and the required commitments should be obtained. The commitments should be translated into legislative and regulatory measures.

Health-in-all-policies approaches, whether governmental, private, or cross-sectoral, should be applied so that living and working in remote areas become pleasant for non-native service providers. Overall, a multi-sectoral approach should be placed on the agenda to provide the necessary situation to increase the motivation of medical graduate students in deprived areas.

This study has some limitations. First of all, in spite of the same process of distribution and recruiting medical graduate students in the deprived areas of Iran, but because of different conditions of working in Iran, as a broad country with different ethnicities, languages, cultural, economic, and social factors, it seems necessary for future studies to consider a broader population to assess the preferences of medical students regarding working in deprived areas. Second, this study merely extracted the preferences for working in underserved regions, so future studies should focus on the effects of different contract clauses on medical group maintenance in these regions. Third, along with this quantitative study, it is necessary for qualitative studies to be performed in the future to extract the lived experiences of medical groups working in deprived areas. Fourth, another limitation of the study is that it has only extracted the preferences of medical groups, not the deprived people. Obtaining these people's preferences would complete the results and remove the blind spots. The fifth and last limitation of the study is about its cross-sectional nature which makes it impossible to present cause and effect relationships.

\section{Conclusion}

Money is not the only factor that affects the decisions of medical sciences students related to working contracts in deprived areas of Iran. The location of a medical center, financial settlements, housing and transportation facilities, duration of contracts, quotations for continuing education, and workload are other main factors. Policymakers should design work contracts that reflect the preferences of 
medical students to increase the probability of recruitment of workforce in deprived areas of the country.

\section{Abbreviations}

DCE, discrete choice experiment; KUMS, Kermanshah University of Medical Sciences; SD, standard deviation; $\mathrm{P}$, p-value; $\beta$, beta coefficient; $\mathrm{CI}$, confidence interval.

\section{Data Sharing Statement}

The datasets used and/or analyzed during the current study are available from the corresponding author on reasonable request.

\section{Ethics Approval and Consent to Participate}

Ethics approval was granted by the Ethics Committee of Kermanshah University of Medical Sciences. All participants in this study provided informed consent.

\section{Acknowledgments}

The authors would like to thank the vice chancellery of research and technology, Kermanshah University of Medical Sciences for its support of this study. Also, we thank all participants in the study.

\section{Author Contributions}

AKK was involved in designing the study. PM, DMR were responsible for data collection. AKK, BKM, SA, SD, SS, and SR were responsible for cleaning data and running statistical analysis and interpretation of the results. All authors have been contributed to writing the first draft of the manuscript. Also, all authors contributed to editing draft versions and accept full responsibility for the content of the manuscript. All authors read and approved the final manuscript.

\section{Funding}

This study was funded by Kermanshah University of Medical Sciences (fund No: 96556).

\section{Disclosure}

The authors declare that they have no competing interests.

\section{References}

1. Mundial B. World Development Report 1993; Investing in Health. Oxford University Press; 1993.

2. Chen L, Evans T, Anand S, et al. Human resources for health: overcoming the crisis. Lancet. 2004;364(9449):1984-1990. doi:10.1016/ S0140-6736(04)17482-5
3. Anbari Z, Mohammadi M, Taheri M. Measurement of quality of hospital services via SERVQUAL model. Life Sci J. 2014;11 (6):51-56.

4. Anand S, Bärnighausen T. Human resources and health outcomes: cross-country econometric study. Lancet. 2004;364(9445):1603-16 09. doi:10.1016/S0140-6736(04)17313-3

5. Robinson JJ, Wharrad H. The relationship between attendance at birth and maternal mortality rates: an exploration of United Nations' data sets including the ratios of physicians and nurses to population, GNP per capita and female literacy. $J$ Adv Nurs. 2001;34 (4):445-455. doi:10.1046/j.1365-2648.2001.01773.x

6. Munga MA, Mæstad O. Measuring inequalities in the distribution of health workers: the case of Tanzania. Hum Resour Health. 2009;7 (1):4. doi:10.1186/1478-4491-7-4

7. Anyangwe SC, Mtonga C. Inequities in the global health workforce: the greatest impediment to health in sub-Saharan Africa. Int J Environ Res Public Health. 2007;4(2):93-100. doi:10.3390/ ijerph2007040002

8. El-Jardali F, Jamal D, Abdallah A, Kassak K. Human resources for health planning and management in the Eastern Mediterranean region: facts, gaps and forward thinking for research and policy. Hum Resour Health. 2007;5(1):9. doi:10.1186/1478-4491-5-9

9. Zarea K, Negarandeh R, Dehghan-Nayeri N, Rezaei-Adaryani M. Nursing staff shortages and job satisfaction in Iran: issues and challenges. Nurs Health Sci. 2009;11(3):326-331. doi:10.1111/ j.1442-2018.2009.00466.x

10. Rezaei S, Kazemi Karyani A, Ghahremani E. Development status and access to health care resources using numerical taxonomy and Morris Model: a case study. Sci J Kurdistan Univ Med Sci. 2015;20 (2):40-50.

11. Sefiddashti SE, Arab M, Ghazanfari S, Kazemi Z, Rezaei S, Karyani AK. Trends of geographic inequalities in the distribution of human resources in healthcare system: the case of Iran. Electron Phys. 2016;8(7):2607. doi:10.19082/2607

12. Mehrdad R. Health system in Iran. JMAJ. 2009;52(1):69-73.

13. Amiresmaili M, Khosravi S, Feyzabadi VY. Factors affecting leave out of general practitioners from rural family physician program: a case of Kerman, Iran. Int J Prev Med. 2014;5(10):1314.

14. Delavari S, Arab M, Rashidian A, Nedjat S, Souteh RG. A qualitative inquiry into the challenges of medical education for retention of general practitioners in rural and underserved areas of Iran. J Prev Med Publ Health. 2016;49(6):386. doi:10.3961/jpmph.16.062

15. Lori JR, Rominski S, Richardson J, Agyei-Baffour P, Kweku NE, Gyakobo M. Factors influencing Ghanaian midwifery students' willingness to work in rural areas: a computerized survey. Int $J$ Nurs Stud. 2012;49(7):834-841. doi:10.1016/j.ijnurstu.2012.02.006

16. Ebadi J, Mehrara M, Tameli S, Sobhanian H. A survey on preferences and factors influencing the decision of the physicians working in public centers of Tehran University of Medical Sciences to enter family physician. J Health Administration. 2014;17:56.

17. Ezatabadi MR, Rashidian A, Shariati M, Foroushani AR, Sari AA. Using conjoint analysis to elicit GPs' preferences for family physician contracts: a case study in Iran. Iran Red Crescent Med J. 2016;18:11.

18. Rafiei S, Arab M, Rashidian A, Mahmoudi M, Rahimi-Movaghar V. Policy interventions to improve rural retention among neurosurgeons in Iran: a discrete choice experiment. Iran $j$ Neurol. 2015;14(4):211.

19. Kazemi Karyani A, Akbari Sari A, Woldemichael A. Eliciting preferences for health insurance in Iran Using discrete choice experiment analysis. Int $J$ Health Policy Manag. 2019;8(8):488-497. doi:10.15171/ijhpm.2019.29

20. Barber S, Bekker H, Marti J, Pavitt S, Khambay B, Meads D. Development of a Discrete-Choice Experiment (DCE) to elicit adolescent and parent preferences for hypodontia treatment. Patient. 2019;12(1):137-148. doi:10.1007/s40271-018-0338-0 
21. Mangham LJ, Hanson K, McPake B. How to do (or not to do) ... Designing a discrete choice experiment for application in a lowincome country. Health Policy Plan. 2008;24(2):151-158. doi:10.10 93/heapol/czn047

22. Liu S, Li S, Yang R, Liu T, Chen G. Job preferences for medical students in China: a discrete choice experiment. Medicine. 2018;97 (38):e12358-e. doi:10.1097/MD.0000000000012358

23. Rockers PC, Jaskiewicz W, Wurts L, et al. Preferences for working in rural clinics among trainee health professionals in Uganda: a discrete choice experiment. BMC Health Serv Res. 2012;12(1):212. doi:10.1186/1472-6963-12-212

24. Robyn PJ, Shroff Z, Zang OR, et al. Addressing health workforce distribution concerns: a discrete choice experiment to develop rural retention strategies in Cameroon. Int J Health Policy Manag. 2015;4 (3):169-180. doi:10.15171/ijhpm.2015.27

25. Hensher DA, Rose JM, Greene WH. Applied Choice Analysis: A Primer. Cambridge University Press; 2005.

26. Ali S, Ronaldson SJ. Ordinal preference elicitation methods in health economics and health services research: using discrete choice experiments and ranking methods. Br Med Bull. 2012;103(1):21-44. doi:10.1093/bmb/lds020

27. Ryan M, Kolstad J, Rockers P, Dolea C How to conduct a discrete choice experiment for health workforce recruitment and retention in remote and rural areas: a user guide with case studies. World Health Organization \& CapacityPlus: World Bank; 2012.

28. Kuhfeld WF. Marketing Research Methods in SAS. Citeseer; 2003.

29. Orme BK. Getting Started with Conjoint Analysis: Strategies for Product Design and Pricing Research. Research Publishers, LLC; 2006.

30. Lancsar E, Louviere J. Conducting discrete choice experiments to inform healthcare decision making. Pharmacoeconomics. 2008;26 (8):661-677. doi:10.2165/00019053-200826080-00004
31. Christiadi, A. and Cushing, B. Conditional logit, IIA, and alternatives for estimating models of interstate migration. Regional Research Institute Publications and Working Papers, 2007(65). https://resear chrepository.wvu.edu/rri_pubs/65

32. Abolhallaje M, Hasani S, Bastani P, Ramezanian M, Kazemian M. Determinants of catastrophic health expenditure in iran. Iran J Public Health. 2013;42(Supple1):155-160.

33. Javanparast S, Baum F, Labonte R, Sanders D, Heidari G, Rezaie S. A policy review of the community health worker programme in Iran. J Public Health Policy. 2011;32(2):263-276. doi:10.1057/jphp.20 11.7

34. Asante AD, Martins N, Otim ME, Dewdney J. Retaining doctors in rural Timor-Leste: a critical appraisal of the opportunities and challenges. Bull World Health Organ. 2014;92(4):277-282. doi:10. 2471/BLT.13.123141

35. Frehywot S, Mullan F, Payne PW, Ross H. Compulsory service programmes for recruiting health workers in remote and rural areas: do they work? Bull World Health Organ. 2010;88(5):364-370. doi:10.2471/BLT.09.071605

36. Darkwa EK, Newman MS, Kawkab M, Chowdhury ME. A qualitative study of factors influencing retention of doctors and nurses at rural healthcare facilities in Bangladesh. BMC Health Serv Res. 2015;15(1):344. doi:10.1186/s12913-015-1012-z

37. Delavari S, Arab M, Rashidian A, Nedjat S, Souteh RG. A qualitative inquiry into the challenges of medical education for retention of general practitioners in rural and underserved areas of Iran. J Prev Med Publ Health. 2016;49(6):386-393.
Risk Management and Healthcare Policy

\section{Publish your work in this journal}

Risk Management and Healthcare Policy is an international, peerreviewed, open access journal focusing on all aspects of public health, policy, and preventative measures to promote good health and improve morbidity and mortality in the population. The journal welcomes submitted papers covering original research, basic science, clinical \& epidemiological studies, reviews and evaluations, guidelines, expert opinion and commentary, case reports and extended reports. The manuscript management system is completely online and includes a very quick and fair peer-review system, which is all easy to use. Visit http://www.dovepress.com/testimonials.php to read real quotes from published authors. 